\title{
ENTRE NEGOCIAÇ̃̃O E CONFLITO: UMA ANÁLISE DA 5a CONFERÊNCIA DE POLÍTICAS PARA AS MULHERES DE SÃO PAULO
}

\author{
BETWEEN NEGOTIATION AND CONFLICT: AN ANALYSIS OF THE $5^{\text {TH }}$ SAO PAULO CONFERENCE ON PUBLIC POLICY FOR \\ WOMEN
}

\section{ENTRE LA NEGOCIACIÓN Y EL CONFLICTO: UN ANÁLISIS DE LA 5 a CONFERENCIA DE POLÍTICAS PARA LAS MUJERES DE SÃO PAULO}

\section{RESUMO}

As conferências de políticas públicas para as mulheres são importantes instâncias de participação social, em que atrizes sociais agem e interagem a fim de influenciar o desenvolvimento de políticas na área. Neste artigo, buscamos compreender os repertórios e estratégias de ação mobilizados na $5^{\text {a }}$ Conferência Municipal de Políticas Públicas para as Mulheres de São Paulo. Com base no estudo de Alvarez e colaboradoras (2003), identificamos três repertórios predominantes: dupla militância, autonomista e institucional. Observamos, ainda, a formação de uma coalizão detentora de poder, constituída pelo governo municipal e pelas organizações próximas a ele, a qual foi desafiada principalmente por mulheres transexuais e travestis, que buscavam maior representatividade na arena. Concluímos este estudo problematizando possíveis implicações para a dinâmica participativa das conferências.

PALAVRAS-CHAVE: Feminismo, gênero, repertório, conferência, política pública para as mulheres.

Mariana Mazzini Marcondes

mariana.mazzini.m@gmail.com

Ana Paula Rodrigues Diniz

anaprdiniz@hotmail.com

Fundação Getulio Vargas, Escola de Administração de Empresas de São Paulo, São Paulo, Brasil

Submetido 08.12.2017. Aprovado 05.04.2018

Avaliado pelo processo de double blind review.

DOI: http://dx.doi.org/10.12660/cgpc.v23n74.73188

Nota: Uma primeira aproximação ao tema foi apresentada no XL Encontro da Associação Nacional de Pós-Graduação e Pesquisa em Administração (ENANPAD), realizado na Costa do Sauípe em 2016. Agradecemos à CAPES pelas bolsas de doutorado concedidas. 


\begin{abstract}
Conferences on public policy for women are relevant spaces for social participation, in which social actresses act and interact to influence the development of gender equality policies. In this paper, we aim to understand the repertoires and action strategies used by participants at the $5^{\text {th }}$ Sao Paulo Conference on Public Policy for Women. Based on Alvarez and contributors (2003), we identified three main repertoires: double militancy, autonomist, and institutional. We also identified a coalition of power holders, formed by the municipal government and organizations close to it. This coalition was challenged mainly by the transgender women group, which was looking to increase their presence at the conference. We finish the paper discussing probable implications for the participative dynamic of conferences.
\end{abstract}

Keywords: Feminism, gender, repertoire, conference, public policy for women.

\title{
RESUMEN
}

Las conferencias de políticas públicas para mujeres son importantes instancias de participación social, en las cuales actrices sociales actúan e interactúan a fin de influenciar el desarrollo de políticas en el área. En este artículo, buscamos comprender repertorios y estrategias de acción movilizados en la $5^{a}$ Conferencia Municipal de Políticas Públicas para las Mujeres de São Paulo. Tomando como base Alvarez y colaboradoras (2003), identificamos tres repertorios predominantes: doble militancia, autonomista e institucional. Observamos, además, la formación de una coalición que detenta el poder, constituida por el gobierno municipal y las organizaciones asociadas a él. Esta fue desafiada principalmente por mujeres transexuales y travestis, que buscaban mayor representatividad en la arena. Concluimos este estudio problematizando implicaciones para la dinámica participativa de las conferencias.

PALABRAS CLAVE: Feminismo, género, repertorio, conferencia, política pública para las mujeres.

\section{INTRODUÇÃO}

Espaços institucionalizados de participação social adquiriram maior centralidade na democratização brasileira nas últimas décadas (Faria, Silva \& Lins, 2012; Souza \& Pires, 2012; Ribeiro et al., 2015). As conferências de políticas públicas se destacaram nesse processo e contribuíram para ampliar a relação entre Estado e Sociedade ao se constituírem em arenas amplas de negociação de diretrizes para a ação estatal, especialmente em nível federal (Rocha, 2008; Avritzer, 2013; Souza et al., 2013). As conferências de políticas para as mulheres são ilustrativas dessa trajetória (Faria, Silva \& Lins, 2012; Ribeiro et al., 2015), pois propõem, avaliam e legitimam iniciativas na área, em todos os níveis da federação.

Acompanhando a valorização dessas inicia- tivas em âmbito governamental, a literatura sobre participação social, em geral, e sobre conferências, em particular, também se ampliou (Avritzer, 2013; Abers, Serafim \& Tatagiba, 2014). Fundamentadas em diferentes arcabouços teóricos e metodológicos - como os relacionados a teorias sobre deliberação pública, movimentos sociais e ação pública -, pesquisas nesse campo têm evidenciado variadas dimensões dessas instâncias participativas, a exemplo de desenhos institucionais adotados, perfil de participantes, relação com o ciclo de políticas públicas, (in)efetividade deliberativa e papel no fortalecimento da democracia no país (Avritzer, 2013; Souza \& Pires, 2012; Abers, Serafim \& Tatagiba, 2014; Ribeiro et al., 2015).

Uma dessas dimensões corresponde às múltiplas interfaces entre Estado e Sociedade (Souza \& Pires, 2012), para as quais 


\section{ENTRE NEGOCIAÇÃO E CONFLITO: UMA ANÁLISE DA 5a CONFERÊNCIA DE POLítICAS PARA AS MULHERES DE SÃO PAULO}

Abers, Serafim e Tatagiba (2014) oferecem uma leitura do caso brasileiro após a eleição de governos de esquerda em nível federal nos anos 2000. Lançando mão do conceito de repertórios de interação, as autoras observam que essa dinâmica se ancorou mais no consenso do que no conflito, tendo em vista o compartilhamento de projetos políticos entre atrizes governamentais e não governamentais. Nesse sentido, elas enfatizam que a experiência nacional desafia a ênfase no conflito destacada nas literaturas internacionais.

Em diálogo com essa abordagem, neste artigo, analisamos as ações e interações ocorridas na $5^{\text {a }}$ Conferência Municipal de Políticas Públicas para as Mulheres de São Paulo (CMPM-SP). Para tanto, partimos da articulação dos conceitos de repertório e estratégia de ação, conforme proposto por Alonso e Mische (2015). Por estratégias de ação, entendemos os modos como atrizes sociais disputam a hegemonia em determinado campo de ação, buscando assegurar a cooperação de outras (Fligstein \& McAdam, 2001). Nessas interações, são empregados diferentes repertórios, compreendidos como conjuntos de modalidades de ação e reivindicação, construídos social e historicamente (Tilly, 2008; Alonso, 2012). Por meio desta pesquisa, buscamos salientar como o conflito constitui uma faceta central da dinâmica das conferências, mesmo em situações em que haja projetos e perspectivas políticas comuns.

A fim de alcançar o objetivo proposto, realizamos uma pesquisa qualitativa, baseada em estudo de caso único. Essa abordagem mostrou-se adequada por viabilizar um exame contextual e em profundidade, articulan- do esforços exploratórios e explicativos, que podem contribuir para a compreensão de casos similares (Stake, 1998; Gibbs, 2009; Gerring, 2010). As conferências foram selecionadas como objeto para análise por constituírem espaços mais amplos de participação social (Rocha, 2008), nos quais é possível observar interações entre diferentes atrizes, governamentais e não governamentais.

A escolha da conferência de São Paulo, por sua vez, orientou-se pelas especificidades contextuais em que ela ocorreu. Naquela época, o Partido dos Trabalhadores (PT) governava o executivo municipal e federal, sendo que parte expressiva das atrizes presentes o integrava ou simpatizava com ele. Seria esperado, portanto, que a dinâmica de interação fosse ditada mais pelo consenso e compartilhamento, tornando os conflitos eventualmente ocorridos de especial interesse analítico.

A coleta de dados foi realizada em duas etapas. Na primeira, fizemos uma aproximação exploratória do campo, por meio da participação em três pré-conferências, entre julho e agosto de 2015. Na ocasião, identificamos os seguintes elementos-chave para a observação da etapa municipal: i. modos de apresentação das participantes, com atenção aos elementos linguísticos (expressões, palavras de ordem, cantos etc.) e não linguísticos (roupas, bandeiras, gestos etc.); ii. demandas e temas defendidos e a relações com as atrizes que os defendem; iii. formas de argumentação; iv. conflitos e formas de negociação; v. organizações e associações presentes.

$\mathrm{Na}$ segunda etapa, realizamos a observa- 
ção participante da $5^{\text {a }}$ CMPM-SP, promovida de 18 a 20 de setembro de 2015. Além das notas de observação, efetuamos registros fotográficos e recuperamos gravações disponibilizadas pela Secretaria Municipal de Política para as Mulheres de São Paulo (SMPM-SP). Esses dados foram registrados em diário de campo e posteriormente categorizados, a fim de compreender os repertórios e as estratégias de ação utilizadas (Gibbs, 2009). Os repertórios foram organizados em torno de três principais modos de ação: i. como as atrizes afirmam sua presença no espaço; ii. como articulam as reivindicações apresentadas; e iii. como negociam conflitos na conferência. As estratégias, por sua vez, derivaram das alianças e oposições estabelecidas, sendo as disputas mais críticas fundamentais para depreender as coalizões formadas.

Por meio da análise, destacamos como os repertórios e estratégias de ação mobilizados na $5^{\text {a }}$ CMPM-SP carregam uma memória da atuação de movimentos sociais e, especialmente, dos feministas e de mulheres no país, recompondo conflitos e alianças de longo prazo. Eles são situados, também, em relação ao contexto social e político mais imediato, o que, no caso estudado, favoreceu alianças entre representantes governamentais e grupos presentes, evidenciando, concomitantemente, a relativa fluidez das fronteiras entre Estado e Sociedade Civil e a heterogeneidade dessa última. As formas de ação observadas, embora condicionadas pelas características institucionais da conferência, não foram por elas determinadas, dando à arena contornos particulares.

Este artigo está estruturado em seis seções, incluindo esta introdução. Na segunda seção, detalhamos o conceito de movimentos sociais, repertórios e estratégias de ação utilizados, assim como os principais conflitos que caracterizam os movimentos feministas e de mulheres latino-americanos e brasileiros. Em seguida, contextualizamos o ressurgimento dos movimentos sociais e a criação e ampliação de espaços de participação social no Brasil, evidenciando como os conflitos mapeados atravessam a realidade nacional. $\mathrm{Na}$ quarta seção, situamos o surgimento e transformação das conferências de políticas públicas e apresentamos o caso analisado, para, na sequência, discutirmos os resultados da investigação. Concluímos problematizando as implicações dos achados para a dinâmica participativa das conferências.

\section{MOVIMENTOS FEMINISTAS E DE MULHE- RES - REPERTÓRIOS E ESTRATÉGIAS DE AÇÃO}

Há uma multiplicidade de abordagens teóricas possíveis para a compreensão dos movimentos sociais (Abers \& Bulow, 2011). Com base no estudo de Della Porta e Dianni (2006), neste trabalho, definimos movimentos sociais como uma dinâmica de ação coletiva inserida em conflitos constitutivos de identidades que relacionam o "nós" aos "outros". Assim, é intrínseco a essa dinâmica definir seus componentes e oponentes, ainda que de modo contraditório e heterogêneo, articulando redes informais e densas com relativa estabilidade. Por meio dessas redes, atrizes sociais organizam e expressam demandas e visões de mundo, tendo nos objetivos comuns a solidariedade. Como observam Martes e Araújo (2016), esse enquadramento privilegia a dinâmica de ação dos movimentos, e não a composição ou institucionalização de participantes. Ao incorpo- 


\section{ENTRE NEGOCIAÇ̃̃o E CONFLITO: UMA ANÁLISE dA 5a CONFERÊNCIA DE POLÍTICAS PARA AS MULHERES DE SÃo PAULO}

rar a noção de rede, reconhece, ainda, que as fronteiras entre Estado e Sociedade não são estanques (Abers \& Bulow, 2011).

Em consonância com essa definição, os movimentos feministas e de mulheres correspondem ao complexo campo de ação que articula pessoas, práticas, ideias e lugares sociais, com o objetivo de melhorar as condições de vida das mulheres (Alvarez, 2014). Embora essas fronteiras não sejam estanques, compreendemos que os movimentos feministas integram os movimentos de muIheres, sendo o elemento diferenciador a identificação daquele com o feminismo, por meio da qual se reivindica uma perspectiva de gênero para a construção de visões de mundo (Silva, 2016). Nesse caso, o patriarcado exerce a função de inimigo comum, podendo, a depender da abordagem defendi$\mathrm{da}$, interseccionar-se com outras formas de opressão, como as de classe e raça.

A interação conflituosa é constitutiva desse campo de ação, tanto na definição de alianças internas, quanto na contraposição ao oponente externo. Nele, atrizes mobilizam diferentes estratégias de ação e repertórios (Alonso \& Mische, 2015), de forma a disputar e negociar a hegemonia em uma arena socialmente construída. Nessas interações, estabelecem-se posições de detentoras de poder e de desafiantes. As primeiras correspondem a grupos ou coalizões que têm um poder desproporcionalmente maior e cujas visões e demandas tendem a prevalecer, enquanto as segundas ocupam lugar menos privilegiado e buscam articular uma visão alternativa, opondo-se às primeiras (Fligstein \& McAdam, 2011).

Nessa polarização, há um compartilhamen- to, ainda que mínimo, sobre o que está em jogo, as regras vigentes e as táticas legitimamente aplicáveis, sendo a disputa deflagrada quando há uma visão difundida de crise ou incerteza sobre as relações de poder no campo. As disputas são mediadas pela necessidade de transcender interesses individuais ou de grupos e podem resultar na recomposição da ordem anterior, na cisão no campo de disputa ou na incorporação de visões e demandas de desafiantes (Alonso, 2009; Fligstein \& McAdam, 2011).

É nessa dinâmica que o que Tilly (2008) denomina por repertórios são aprendidos e reinventados. Os repertórios correspondem a formas de ação e reivindicação relativamente estáveis, construídas social e historicamente. Em um dado contexto, atrizes mobilizam um número limitado de repertórios (Tilly, 2008), os quais funcionam como caixas de ferramentas de maneiras de fazer política naquele momento (Alonso, 2012; Abers, Serafim \& Tatagiba, 2014).

Como destacam Abers, Serafim e Tatagiba (2014), a ênfase desse conceito não está no conteúdo da ação, mas em sua forma. Assim, embora determinados modos de ação sejam usualmente associados a grupos específicos - como, por exemplo, a ocupação de terras pelo Movimento Sem Terra (MST) ou a realização de greves por sindicatos (Rocha, 2008) -, essas práticas não apresentam um significado em si, sendo empregadas por interesses defendidos e pelas circunstâncias de atuação. Esse processo é dependente, também, de elementos históricos, da cultura política e da tradição, sendo que a memória de interações pretéritas condiciona as práticas subsequentes, ainda que essas mesmas práticas sejam (re)inventa- 
das na interação conflituosa (Tilly, 2008).

No que diz respeito aos movimentos feministas e de mulheres no Brasil, essas disputas e negociações, embora apresentem particularidades locais, não estão descoladas do contexto histórico mais amplo, especialmente do latino-americano (Costa, 2005). Como destacou Bezerra (2014) ao investigar os repertórios e estratégias de ação utilizados por movimentos feministas e de mulheres nacionais, as articulações regionais são centrais para a dinâmica desses movimentos, como as promovidas nos Encontros Feministas Latino-Americanos e Caribenhos.

Por meio da análise dos 20 anos dos Encontros Feministas Latino-Americanos e Caribenhos, Alvarez e colaboradoras (2003) identificam três conflitos predominantes em nível regional. O primeiro refere-se à tensão entre dupla militância e feminismo autonomista. Segundo as autoras, no contexto de redemocratização regional, mulheres identificadas com o feminismo optaram por construir trajetórias políticas também em partidos, sindicatos e movimentos populares, os quais apresentam lógicas de ação distintas e, em alguns casos, opostas às dos movimentos feministas e de mulheres. Essa dupla militância foi contestada pelo feminismo autonomista, que reivindicou uma atuação que priorizasse a luta contra as especificidades da opressão patriarcal.

A institucionalização foi outro evento que demarcou clivagens. Essa remete à ONGização dos movimentos sociais e ao envolvimento de militantes e organizações em esforços de advocacy, inclusive financiadas por instituições internacionais e governa- mentais. Refere-se, também, à participação de militantes em encontros promovidos por organizações internacionais, como a Organização das Nações Unidas (ONU). Pode ser associada, por fim, à institucionalização da política para as mulheres em nível nacional e internacional, levando feministas a ocupar cargos na burocracia estatal e em organismos internacionais. $O$ resultado foi a maior especialização técnica, em que dominar a linguagem institucional, legal e do campo das políticas públicas passou a ser um diferencial de atuação (Alvarez et al., 2003).

Por fim, Alvarez e colaboradoras (2003) discutem as tensões em torno da adoção de um sujeito feminino universal, a despeito da diversidade existente entre as mulheres. Nesse caso, a reflexão e ação feminista seria amparada em uma noção unívoca de mulher, sendo as questões de gênero desassociadas de outros eixos de opressão, como raça, classe e sexualidade. Mulheres negras, lésbicas, transexuais, travestis, entre outras, têm problematizado, contudo, que essa noção é excludente, negligenciando sujeitos e demandas que se afastem desse ideal (Bento, 2009; Butler, 2010). Nesse contexto, o feminismo deveria compreender as desigualdades de forma interseccional (Crenshaw, 2002), evidenciar a pluralidade e as desigualdades entre as mulheres e garantir a abertura para a inclusão de novos sujeitos e reivindicações (Butler, 2010).

Fundamentado nesse enquadramento teórico, neste artigo, investigamos as formas de ação e interação mobilizadas pelas participantes da $5^{\text {a }}$ CMPM-SP, a fim de influenciar os resultados dessa instância participativa. Por meio da análise do caso, salientamos como os conflitos identificados por Alvarez 
e colaboradoras (2003) continuam atuais e fornecem importantes subsídios para a apreensão dos repertórios mobilizados pelos movimentos feministas e de mulheres na contemporaneidade. Para tanto, preliminarmente, apresentamos um breve histórico do ressurgimento dos movimentos sociais no Brasil, evidenciando como esses conflitos atravessam a realidade nacional.

\section{BREVE HISTÓRICO DOS MOVIMENTOS FEMINISTAS, DE MULHERES E DAS INS- TÂNCIAS PARTICIPATIVAS NO BRASIL}

O histórico do ressurgimento dos movimentos sociais brasileiros remete à luta contra ditaduras militares, nos anos 1960 . O período ditatorial caracterizou-se por um cotidiano de violência que impedia toda e qualquer mobilização política e pela quase inexistência de canais institucionais para expressão de demandas sociais (Cardoso, 2008; Gohn, 2008; Rocha, 2008). No entanto, a despeito da forte repressão, nos anos 1970 e 1980, atrizes sociais passaram a se organizar "de costas para o Estado" (Rocha, 2008, p. 134), articulando-se em torno de reivindicações pela ampliação de direitos sociais e pela melhoria das condições de vida (Cardoso, 2008).

Nesse cenário, assistiu-se à emergência dos novos movimentos sociais (Rocha, 2008), que tiveram papel fundamental na redemocratização nacional. Entre as atrizes emergentes, destacaram-se os movimentos populares rurais e urbanos, articulados em torno de demandas relacionadas à saúde, à educação e à habitação, assim como partidos políticos de massa (Veras, 2005; Keck, 2010) e novas formas de organização sindical, gestadas nas ondas de greves em indústrias metalúrgicas e automobilísticas do ABC paulista (Souza-Lobo, 1991; Veras, 2005). Entraram em cena, também, forças sociais que reivindicavam mudanças a partir da mobilização de grupos específicos, como os movimentos feministas e de mulheres, os movimentos de lésbicas, gays, bissexuais, transexuais e travestis (LGBTT) e os movimentos negros (Costa, 2005; Bezerra, 2014).

Para os movimentos feministas e de muIheres, convergiu uma heterogeneidade de atrizes, provenientes tanto dos partidos, sindicatos e movimentos populares, quanto de clubes de mães e de outros setores sociais, como o estudantil, intelectual e de profissionais liberais (Costa, 2005). Isso resultou em uma pluralidade de reivindicações, desde as associadas à agenda feminista, como a garantia de direitos sexuais e reprodutivos, até a melhoria das condições de vida em geral, como acesso à saúde e à moradia (Bezerra, 2014; Silva, 2016). Resultou, também, em diferentes formas de organização. De um lado, o autonomismo ganhou força, defendendo-se o protagonismo das mulheres e da luta contra o patriarcado (Costa, 2005). De outro, essas mulheres atuavam também em partidos, sindicatos e movimentos populares (Souza-Lobo, 1991), levando a descontinuidades e conflitos, como o entre dupla-militância e feminismo autonomista discutido por Alvarez e colaboradores (2003).

Paralelamente e, em larga medida, em resposta à atuação desses movimentos, foram instituídos os primeiros espaços participativos. A Constituição Federal de 1988 foi um marco nesse processo, pois enfatizou a importância da participação social na vida estatal e estabeleceu mecanismos institucionais, como os conselhos e as conferên- 
cias de políticas públicas (Rocha, 2008). Por meio da atuação nesses espaços, os movimentos sociais buscavam mudanças não só em comportamentos sociais, mas também nas políticas públicas (Abers \& Bulow, 2011). Deixavam, assim, de estar "de costas para o Estado", contribuindo para deslocar as fronteiras entre Estado e Sociedade Civil. No caso dos movimentos feministas e de muIheres, os anos 1980 inauguraram importantes medidas nesse sentido, como o ConseIho Estadual da Condição Feminina, em São Paulo, e o Conselho Nacional dos Direitos da Mulher (CNDM) (Costa, 2005; Bezerra, 2014; Silva, 2016).

No mesmo período, observou-se um crescente intercâmbio dos movimentos nacionais em espaços internacionais. Nos movimentos feministas e de mulheres, esse processo se iniciou com a declaração do Ano Internacional da Mulher pela ONU, em 1975, e foi intensificado com a criação de diferentes esferas de articulação entre atrizes da Sociedade Civil em nível regional e internacional, como o citado Encontro Feminista Latino Americano e Caribenho (Costa, 2005; Bezerra, 2014; Silva, 2016) e as Conferências Mundiais da Mulher, realizadas no México em 1975 e em Nairóbi em 1985 (Bandeira, 2005). A participação nessas esferas e a maior aproximação da burocracia estatal contribuíram para (re)criar perspectivas e práticas utilizadas. Isso não se deu, contudo, sem resistências, pois culminou em conflitos como o institucionalista, discutido por Alvarez e colaboradoras (2003).

Os anos 1990 marcaram uma inflexão nesse processo. Com a ascensão do neoliberalismo, iniciativas governamentais de participação social foram desmobilizadas (Rocha,
2008), a exemplo do recém-criado CNDM (Costa, 2005). O novo cenário político provocou, também, uma reconfiguração na atuação da Sociedade Civil, com transferência de responsabilidades estatais para Organizações Não Governamentais, que passaram a oferecer serviços relacionados a suas áreas de atuação (Rocha, 2008). Contribuiu para esse processo a crescente institucionalização de organizações de movimentos sociais, inclusive estimulada por organismos internacionais (Gohn, 2008). Ao mesmo tempo, outros conflitos afloraram. O fortalecimento dos feminismos, como o popular, negro, rural e LBTT, tensionou os sentidos de uma luta pela igualdade que invisibilizava as diferenças e múltiplas formas de desigualdades (Costa, 2005; Silva, 2016).

Posteriormente, nos anos 2000, ocorreu na América Latina o que Filgueira (2013) denomina por "giro à esquerda", em que coalizões progressistas foram eleitas para implementar projetos de garantia de direitos, redução de desigualdades e democratização de instâncias estatais. No caso brasileiro, isso significou a ascensão do PT ao governo nacional e, com ele, de forças políticas originárias do sindicalismo e dos novos movimentos sociais. Um efeito dessa nova conjuntura foi a reativação e a ampliação de mecanismos de participação social, como conferências e conselhos (Rocha, 2008), que passaram a abranger diferentes áreas de políticas públicas, especialmente em nível federal (Souza et al., 2013).

Nesse contexto, a próxima seção aborda as conferências de políticas públicas, destacando tanto características desses espaços participativos, quanto especificidades do caso estudado. 


\section{ENTRE NEGOCIAÇ̃̃o E CONFLITO: UMA ANÁLISE dA 5a CONFERÊNCIA DE POLÍTICAS PARA AS MULHERES DE SÃo PAULO}

\section{AS CONFERÊNCIAS DE POLÍTICAS PARA AS MULHERES - SITUANDO O CASO ES- TUDADO}

As conferências de políticas públicas surgiram no Brasil na Era Vargas. Realizadas em 1941, as primeiras conferências de saúde e educação eram vistas como instrumentos para articulação federativa e aprimoramento administrativo, pois visavam contribuir para a ampliação da capacidade de execução dos programas e estabelecer parâmetros mais claros para atuação e relação entre os entes. Desde sua criação, observou-se uma mudança substantiva dos objetivos e modelos adotados nessas instâncias, migrando, paulatinamente, para um modelo descentralizado e comprometido com a ampliação da participação social (Souza et al., 2013). Após a Constituição de 1988, as conferências passaram a compor a estrutura gestora de políticas públicas, sendo realizadas em diferentes setores de atuação governamental (Avritzer \& Souza, 2013).

Nessa nova configuração, as conferências podem ser entendidas como "canais institucionais de participação social, caracterizados como processos periódicos de diálogo entre Estado e sociedade a respeito de um tema" (Ribeiro et al., 2015:58). Nelas, são negociados conflitos entre representantes estatais e não estatais (Souza \& Pires, 2012), com o objetivo de construir uma agenda pública (Ramos, 2013) para influenciar as ações governamentais em determinada área. Esse processo é marcado pela mobilização social e participação plural, potencializada pela conexão entre conferências municipais, distritais, estaduais e nacionais, em que são definidas prioridades e eleitas representantes para as etapas seguintes (Ribeiro et al., 2015). São condicionadas, ainda, pelo contexto social e político, além de atenderem a regulamentações específicas, que normatizam esse arranjo (Avritzer, 2013).

No entanto, como mencionado, foi no governo Lula (2003-2010) que se observou a intensificação do uso dessas instâncias participativas, envolvendo uma pluralidade de órgãos e de questões abordadas (Souza et al., 2013). Como salientam Avritzer e Souza (2013), até 2012 foram realizadas 128 conferências nacionais, das quais $67 \%$ ocorreram entre 2003 e 2012. Foi nesse período que se realizaram as primeiras Conferências Nacionais de Políticas Públicas para as Mulheres (CNPM). Inaugurada em 2004, a CNPM já contou com quatro edições. Por meio delas, buscou-se propor, avaliar e legitimar iniciativas governamentais para as mulheres e para a igualdade de gênero, subsidiando tanto o desenvolvimento da Política e dos Planos Nacionais de Políticas para as MuIheres, quanto de programas e ações em nível subnacional (Marcondes, Diniz \& Farah, 2016).

A cidade de São Paulo participou de todas as CNPMs, tendo promovido uma conferência independente em 2002. Com o tema "Participação, Políticas Públicas e Consolidação de direitos: construindo o Plano Municipal de Políticas para as Mulheres", a $5^{\text {a }}$ CMPM-SP ocorreu de 18 a 20 de setembro de 2015, sendo precedida por 23 pré-conferências para mapeamento de propostas e mobilização social (Prefeitura de São Paulo, 2015a). A etapa municipal visou indicar propostas e eleger delegadas para a estadual; avaliar as políticas para as mulheres na ci- 
dade, e construir insumos para o primeiro plano municipal na área. Para tanto, contou com a seguinte programação: solenidade de abertura; painéis sobre o Plano Municipal de Políticas para as Mulheres e para apresentação das ações da SMPM-SP; Plenária de Abertura, com aprovação do regulamento interno; Grupos Temáticos de Discussão (GTs), e Plenária final, com votação das resoluções, moções e eleição de delegadas (Prefeitura de São Paulo, 2015b).

Ao longo de seus três dias de realização, a $5^{a}$ CMPM-SP reuniu mais de 1.400 participantes de diferentes regiões da cidade (Prefeitura de São Paulo, 2017). Desde a solenidade de abertura, era possível identificar a presença de organizações vinculadas a diversos movimentos sociais, reforçada por bandeiras hasteadas no espaço das plenárias, coletes de identificação, camisetas e acessórios personalizados. As organizações presentes de maneira mais ostensiva eram partidos de esquerda, sindicatos e associações do movimento de moradia.

No caso dos partidos, havia principalmente mulheres do PT e do Partido Comunista do Brasil (PCdoB). Já em relação aos sindicatos, a entidade com maior número de representantes era a Central Única dos TrabaIhadores (CUT), estando presentes também outras organizações, como a Central dos Trabalhadores do Brasil, a União Geral dos Trabalhadores e a Força Sindical. Havia, ainda, associações do movimento de moradia, como a Frente de Luta por Moradia, a União Nacional de Moradia Popular, a Unificação das Lutas de Cortiço e Moradia e a União de Movimentos de Moradores de São Paulo. Organizações de movimentos feministas também estavam representadas. A Marcha
Mundial das Mulheres era a organização mais visível, embora participassem, também, a Articulação das Mulheres Brasileiras, a União Brasileira de Mulheres e a Confederação de Mulheres do Brasil, entre outras, que se identificavam por meio de camisetas e faixas. Somavam-se a elas organizações vinculadas ao movimento negro, feministas ou não, como a Articulação das Mulheres Negras do Brasil, a União de Negros pela Igualdade, a Coordenação Nacional de Entidades Negras e a Marcha das Mulheres Negras. As mulheres negras afirmavam sua presença tanto por meio de bandeiras das organizações, quanto pelo uso de turbantes, indumentárias e outros artefatos afro.

Mulheres lésbicas também se colocavam no espaço, embora com menor visibilidade que as transexuais e travestis, que acabaram por constituir uma importante força na conferência. Esses grupos estavam identificados por bandeiras coloridas e roupas, cabelos e maquiagens exuberantes. Da mesma forma, imigrantes e indígenas afirmavam sua presença por meio de trajes, podendo ser identificadas, ainda, pelas demandas apresentadas.

Por meio das reivindicações, era possível observar, ainda, a presença de representantes dos direitos de pessoas com deficiência, conselheiras municipais, integrantes dos fóruns regionais e mulheres sem vinculação organizacional prévia. As principais demandas colocadas por esses grupos estavam relacionadas às necessidades concretas de serviços e políticas, problematizadas, sobretudo, sob a perspectiva regional, como, por exemplo, a reivindicação por melhoria dos serviços de Unidades Básica de Saúde (UBS) em determinados distritos da cidade. 


\section{ENTRE NEGOCIAÇÃO E CONFLITO: UMA ANÁLISE DA 5a CONFERÊNCIA DE POLítICAS PARA AS MULHERES DE SÃO PAULO}

Conflitos puderam ser observados ao longo de toda a conferência. A principal arena de disputa ocorreu durante a Plenária de Abertura e girou em torno da definição de regras para escolha de representantes da Sociedade Civil para a etapa estadual. Outra forte disputa foi travada durante a votação das moções, na Plenária Final. A observação dos conflitos, de maneira geral, e, em especial, dos eventos mais críticos foram fundamentais para a identificação dos repertórios e estratégias de ação mobilizados. Os repertórios foram organizados em torno de três formas de ação principais: i. demarcação da presença das atrizes; ii. articulação das reivindicações; iii. negociação de conflitos. As estratégias, por sua vez, derivaram das alianças e oposições estabelecidas, como discutiremos na seção seguinte.

\section{REPERTÓRIOS E ESTRATÉGIAS DE AÇÃO NA $5^{\text {a }}$ CONFERÊNCIA DE POLÍTI- CAS PARA AS MULHERES DA CIDADE DE SÃO PAULO}

A 5a CMPM-SP ocorreu em uma conjuntura política de forte contestação do governo federal e do PT, partido que liderava o Executivo nacional e municipal. Os posicionamentos em relação a essa conjuntura foram evidenciados ao longo de toda a conferência, havendo manifestações de apoio à Presidenta Dilma Rousseff, desde as primeiras falas e ações da solenidade de abertura. Essa conjuntura política, somada à expressiva presença de grupos aliados ao partido, favoreceu a articulação de uma coalizão detentora de poder (Alonso, 2009; Fligstein \& McAdam, 2011), composta, principalmente, por representantes governamentais, de partidos, sindicatos e movimentos populares.
Essa coalização mobilizou, especialmente, o repertório que denominamos, a partir dos conflitos identificados por Alvarez e colaboradoras (2003), por dupla militância. Por meio dele, práticas comumente associadas aos movimentos feministas e de mulheres foram articuladas às relacionadas aos partidos e sindicatos. A presença de atrizes e grupos foi afirmada, principalmente, por meio da demonstração pública de filiação organizacional, manifestada por meio de diferentes artefatos utilizados, como bandeiras, camisetas, broches e coletes estampados com símbolos de partidos, associações e sindicatos - como a estrela do PT, a foice e machado do PCdoB e o logo da CUT. Essa filiação foi reforçada pelo uso do termo "companheira" para se referirem umas às outras, utilizado pela maioria das participantes especialmente nas falas abertas ao plenário.

O vínculo organizacional pôde ser depreendido, também, pelas reivindicações articuladas nessa coalizão, as quais estavam fortemente associadas à garantia de direitos trabalhistas e à ampliação de políticas sociais, como a diminuição de jornada de trabalho sem redução salarial e a destinação de $100 \%$ dos royalties do Pré-Sal para a educação pública, respectivamente. Essas pautas nem sempre foram problematizadas na perspectiva de gênero, demarcando a vivência da dupla militância por essas mulheres. Essa tática favoreceu, ainda, alianças com movimentos de moradia e mulheres de bairro, que demandavam ações governamentais para lidar com as necessidades concretas do cotidiano, especialmente nas regiões mais empobrecidas da cidade.

O modo prioritário de negociação nesse repertório se aproximou do denominado cen- 
tralismo democrático (Keck, 2010), destacando-se a concentração de decisões nas lideranças e um intenso engajamento da militância de base para sua legitimação. $O$ protagonismo das lideranças ocorreu, sobretudo, na negociação de conflitos que surgiam na plenária em grupos paralelos, em uma espécie de mesa de negociação tripartite improvisada. Nesse espaço, as partes envolvidas, mediadas por representantes governamentais, debatiam temas e propunham opções para votação, de modo a encaminhar uma proposta pré-acordada para a plenária e, assim, evitar os desgastes do debate mais amplo. A legitimidade das lideranças vinha de suas bases, que votavam efusivamente segundo as orientações pré-acordadas, com uso de palavras de ordem que, ao ecoarem no plenário, demonstravam a força dessa coalizão.

A força dessa coalizão foi evidenciada, também, no conflito em torno de uma moção de repúdio ao impeachment da presidenta Dilma Rousseff. Após ter sido aprovada com aplausos e gritos de "não vai ter golpe", uma das delegadas, identificada pelas demais como uma voz dissonante, pediu a palavra para apresentar uma crítica à política econômica do governo federal. Em resposta, participantes puxaram palavras de ordem em defesa do governo e da presidenta como "no meu país eu boto fé, porque ele é governado por mulher" -, incendiando 0 plenário, que se levantou para cantar e dançar, impedindo que a delegada concluísse sua fala. Nesse contexto, observamos, mais uma vez, a importância da militância de base, apoiando efusivamente as lideranças da coalizão detentora de poder e excluindo, se necessário, desafiantes da arena.
Outro conflito emblemático ocorreu durante a votação das regras para a eleição da delegação que seguiria para a etapa estadual. A proposta em discussão definia que as delegadas da Sociedade Civil seriam eleitas em plenária própria, sendo $60 \%$ representantes de entidades e movimentos com atuação comprovada na temática de gênero e $40 \%$ representantes das regiões da cidade (Prefeitura de São Paulo, 2015b). Em contraposição, as transvestis e transexuais, apoiadas pelas mulheres lésbicas, reivindicaram uma cota de participação para o grupo, a fim de evitar a baixa representação observada em conferências anteriores. O tema era sensível, pois colocava em xeque a acomodação da ampla base de integrantes da coalizão detentora de poder na delegação. Buscava-se, assim, alterar as regras do jogo estabelecidas no regulamento, desprivilegiando os grupos hegemônicos e permitindo algum nível de ascensão das desafiantes.

Nesse conflito, observamos a emergência de outro repertório, denominado identitário. As formas de ação características desse repertório remetiam principalmente às especificidades do feminino e das vivências da opressão patriarcal, ora valorizando, ora invisibilizando as diferenças e desigualdades entre as mulheres. Por um lado, atrizes e grupos afirmavam sua presença por meio da demonstração pública de pertencimento identitário, ostentando artefatos e símbolos associados a grupos específicos, como, por exemplo, o uso de turbantes por mulheres negras e de cocares pelas indígenas. Esse pertencimento era reforçado por reivindicações em prol da visibilização das desigualdades entre as mulheres e do desenvolvimento de políticas focalizadas, como programas de autonomia econômica para mulheres negras, 


\section{ENTRE NEGOCIAÇ̃̃o E CONFLITO: UMA ANÁLISE dA 5a CONFERÊNCIA DE POLÍTICAS PARA AS MULHERES DE SÃo PAULO}

ações de alfabetização para idosas e institucionalização do nome social para travestis e transexuais.

Por outro lado, a "mulher", como sujeito universal, também era mobilizada. Essa noção amparou reivindicações em prol de direitos e melhorias nas condições de vida em geral, como na defesa ao Projeto de Lei Complementar n. 130, que reforça mecanismos para a igualdade salarial entre mulheres $e$ homens. Foi reafirmada, também, nos casos em que as diferenças foram utilizadas para diluir as múltiplas formas de desigualdade e, assim, reafirmar a mulher como sujeito uno. Isso ocorreu, por exemplo, quando a Comissão Organizadora propôs a inserção de uma nota que listasse as múltiplas identidades contidas na expressão mulher, em vez de trabalhar as intersecções em cada uma das resoluções. Em decorrência disso, resoluções, anteriormente voltadas para grupos específicos, tornavam-se universais.

$\mathrm{Na}$ disputa protagonizada pelas transexuais e travestis, as desafiantes combinaram o confronto direto com a coalizão detentora de poder - denunciando a não aceitação das travestis e transexuais como mulheres - com a busca por empatia da plenária advogando, também, por maior visibilidade para outros grupos, como o de idosas. Optaram, ainda, pela negociação mais ampla e horizontal, valorizando falas na plenária e evitando o que chamamos de mesa de negociação tripartite improvisada, que ocorria no canto lateral do palco e amadurecia os acordos para votação. Por meio dessas ações, as desafiantes buscavam firmar um compromisso coletivo com maior pluralidade da representação e com a participação de um grupo fortemente discriminado. Ao fim, duas representantes de mulheres transexuais e uma das travestis foram incluídas na delegação, reestabelecendo a ordem no campo sem resultar em cisão.

Em meio aos conflitos, observamos, também, a relevância do domínio das normas e de outras especificidades técnicas associadas a essa arena. Na votação do regulamento, atrizes mais fluentes nas regras formais se destacaram, colocando-se, inclusive, como validadoras ou autorizadoras das estratégias utilizadas pelas demais participantes. A mobilização de conhecimento específico como um diferencial na disputa pode ser associada ao terceiro repertório, que nomeamos, a partir de Alvarez e colaboradas (2003), por institucional. Nele, argumentos técnicos são empregados, utilizando-se tanto do conhecimento científico, profissional e da dinâmica da conferência, quanto da posição institucional ocupada pela participante para legitimar sua ação.

Esse repertório foi recorrente nos GTs, posicionando especialistas como autoridades em áreas profissionais ou nos debates sobre gênero e feminismo, aptas a traduzir reivindicações de mulheres menos experientes nos temas discutidos. Isso ocorreu, sobretudo, em relação a demandas apontadas pelo movimento de mulheres, especialmente das regiões mais empobrecidas da cidade, que reivindicavam melhorias de serviços locais, como o prestado por UBSs. Militantes da área da saúde das mulheres atuavam conjuntamente para expressar essas reivindicações em termos alinhados com os consagrados nos movimentos, nas políticas e nos planos para as mulheres. Essa tradução não era, contudo, neutra, e conformava as demandas às perspectivas ou visões do grupo 
ao qual pertencia a tradutora.

\section{REFLEXÕES FINAIS}

Este artigo teve como objetivo investigar os repertórios e as estratégias de ação mobilizados na $5^{\text {a }}$ CMPM-SP. Por meio da análise qualitativa do caso, depreendemos três repertórios, que denominamos, com base nos conflitos identificados por Alvarez e colaboradores (2003), de dupla militância, identitário e institucional. Esses foram diferenciados em relação às formas como as atrizes se posicionaram na arena, articularam as reivindicações apresentadas e negociaram as disputas travadas. Observamos, também, a composição de diferentes alianças e oposições na conferência, demarcando posições no campo, entre as quais identificamos uma coalizão detentora de poder e diferentes desafiantes (Alonso, 2009; Fligstein \& McAdam, 2011; Alonso \& Mische, 2015).

$\mathrm{Na}$ dupla militância, práticas comumente associadas a partidos e sindicados foram recuperadas. A demonstração pública de filiação organizacional constituiu-se a forma prioritária de demarcação de espaço na arena, sendo reafirmada por meio de reivindicações ligadas à crítica ao capitalismo e à garantia de direitos trabalhistas, nem sempre problematizadas na perspectiva de gênero. Somou-se a isso o uso de modos de negociação mais hierarquizados e centralizados nas lideranças, que identificamos como uma expressão do centralismo democrático (Keck, 2010).

Em contrapartida, o repertório identitário privilegiou formas horizontais de negociação e amparou suas reivindicações nas especificidades do feminino e da opressão patriar- cal, que ora valorizavam, ora invisibilizavam as diferenças e desigualdades entre as muIheres. O repertório institucional, por fim, caracterizou-se pelo uso do conhecimento e da linguagem técnica como meio principal de ação e negociação, legitimando atrizes como autoridades e tradutoras na conferência.

O cenário de forte contestação do governo federal e do PT, somada à expressiva presença de atrizes aliadas ao partido, favoreceu a formação de uma coalizão detentora de poder, composta principalmente por representantes governamentais, de partidos de esquerda, sindicatos e movimentos populares. Essa coalizão foi contestada em diferentes momentos, sendo dois conflitos emblemáticos. No primeiro, houve a crítica à política econômica federal em vigor, direcionada em resposta ao amplo apoio à moção contra o impeachment da Presidenta Dilma. O segundo envolveu a demanda por cotas de participação na delegação a ser eleita, vocalizada principalmente pelas mulheres transexuais e travestis.

As soluções foram, contudo, diversas. No primeiro caso, a crítica ao governo federal foi expelida do plenário, ocorrendo uma cisão no campo. No segundo, as desafiantes foram incorporadas ao acordo final, garantindo a representatividade do grupo na delegação e, com isso, a reordenação das relações de poder.

Por meio da análise realizada, evidenciamos como a ação e a interação das atrizes na conferência são situadas, combinando a memória da atuação dos movimentos e elementos da conjuntura política com os desenhos e regras desse espaço participativo. Nesse contexto, a conferência se torna palco não só de negociação de uma agenda de políticas 


\section{ENTRE NEGOCIAÇ̃̃o E CONFLITO: UMA ANÁLISE dA 5a CONFERÊNCIA DE POLÍTICAS PARA AS MULHERES DE SÃo PAULO}

públicas para as mulheres, mas também de reencenação de disputas, relacionadas tanto às dinâmicas internas dos movimentos $\mathrm{e}$ quanto ao contexto político amplo.

Os repertórios e estratégias de ação empregados nessa interação conflituosa, embora não rompam com as regras formais das conferências, dão a elas novos contornos. A composição da mesa de negociação tripartite é exemplar desse processo, deslocando o debate da plenária, como esperado, para grupos paralelos, compostos por lideranças organizacionais e intermediados por representantes governamentais.

Por esse motivo, ressaltamos, em concordância com Abers, Serafim e Tatagiba (2014), que as conferências não se resumem a suas regras e ritos formais, mas derivam de uma combinação de características institucionais com elementos contextuais e especificidades das atrizes que as ocupam, sendo os resultados de cada arena um tanto imprevisíveis. No entanto, embora o compartilhamento de projetos políticos entre representantes governamentais e não governamentais seja relevante nesse processo, ele não necessariamente implica interações fundadas no consenso. Como buscamos evidenciar, o conflito persiste uma dimensão fundamental da dinâmica dessas instâncias participativas, mesmo em situações em que haja parâmetros políticos e ideológicos comuns.

Isso implica deslocar o olhar da tensão Estado-Sociedade Civil para uma pluralidade de conflitos e alianças, e reconhecer os limites dessa dicotomia para a compreensão de espaços participativos. Como identificamos no caso estudado, as coalizões constituídas variam de acordo com o contexto em que são realizadas as conferências e das atrizes nelas presentes, podendo inclusive articular atrizes estatais e da Sociedade Civil, de um lado, e outras integrantes dos movimentos sociais, de outro. Isso também reflete a heterogeneidade de práticas, valores e demandas reunidas sob a nomenclatura Sociedade Civil, importante para a compreensão das formas de ação e interação mobilizadas.

Por meio deste artigo, buscamos contribuir para a reflexão sobre as conferências em suas dinâmicas contextuais, valorizando a dimensão do conflito. Para tanto, recorremos a arcabouços teóricos sobre movimentos sociais e, especialmente, sobre os feministas e de mulheres, a fim de jogar luz sobre as relações de poder estabelecidas nessa arena. Como limitações deste artigo, destacamos a realização de um estudo de caso único, não sendo possível generalizar os resultados encontrados. Isso sugere, também, o desenvolvimento de novas pesquisas e a exploração das especificidades das conferências de políticas públicas, promovidas tanto por entes e em esferas federativas distintas, quanto pelo palco da atuação de outros movimentos sociais.

\section{REFERÊNCIAS}

Abers, R., Bulow, M. U. (2011). Movimentos sociais na teoria e na prática: Como estudar 0 ativismo através da fronteira entre estado e sociedade? Sociologias, 13(28), 52-84

Abers, R., Serafim, L., Tatagiba, L. (2014). Repertórios de interação estado-sociedade em um estado heterogêneo: A experiência na Era Lula. Dados, 57(2), 325-357. 
Alonso, Â. (2009). As teorias dos movimentos sociais: Um balanço do debate. Lua Nova, (76), 49-86.

Alonso, Â. (2012). Repertório, segundo Charles Tilly: História de um conceito. Sociologia \& Antropologia, 2(3), 21-41.

Alonso, Â., Mische, A. (2015). June demonstrations in Brazil: Repertoires of contention and government's response to protest. In: Esa research network on social movements - midterm conference (pp. 1-37) .Madrid. Anais... Madrid: Esa, p.

Alvarez, S. E. (2014). Para além da sociedade civil: Reflexões sobre o campo feminista. Cadernos Pagu, (43), 13-56.

Alvarez, S. E., Friedman, E. J., Beckman, E. Blackwell, M., Chinchila, N. S., Lebon, N. ... Tobar, M. R. (2003). Encontrando os feminismos latino-americanos e caribenhos. $R e-$ vista de Estudos Feministas, 11(2), 541-575.

Avritzer, L., Souza, C. H. L. de. (2013). Conferências nacionais: entendendo a dinâmica de participação no nível nacional. In: Avritzer, Leonardo; Souza, C. H. L. de (Orgs). Conferências Nacionais: atores, dinâmicas participativas e efetividade. Brasília: IPEA, pp. 9-21.

Avritzer, L. (2013). Conferências Nacionais: ampliando e redefinindo os padrões de participação social no Brasil. In: Avritzer, Leonardo; Souza, Clóvis H. L. de (Orgs.). Conferências Nacionais: atores, dinâmicas participativas e efetividade (pp. 125-140). Brasília: IPEA.

Bandeira, L. (2005). Brasil: Fortalecimento da secretaria especial de políticas para as mulheres para avançar na transversalização da perspectiva de gênero nas políticas públicas. In: A pobreza e as políticas de gênero no Brasil, Serie Mujer y desarrollo (pp. 4376). Cepal.

Bento, B. (2009). A diferença que faz a diferença: Corpo e subjetividade na transexualidade. Bagoas, (4), 95-112.

Bezerra, C de P. (2014). Movimento feminista brasileiro: Repertórios e estratégias de ação. Feminismos, 2(1), 47-55.

Butler, J. (2010). Problemas de gênero: Feminismo e subversão da identidade. 3. ed. Rio de Janeiro: Civilização Brasileira.

Cardoso, R. (2008). Movimentos sociais urbanos: Balanço crítico. In: Sorj, Bernardo; Almeida, Maria Hermínia T. de. (Orgs.). Sociedade política no Brasil pós-64 (pp. 313-350). Rio de Janeiro: Centro Edelstein de Pesquisas Sociais.

Costa, A. A. A. (2005). O movimento feminista no Brasil: Dinâmicas de uma intervenção política. Gênero, 5(2), 9-35.

Crenshaw, K. (2002). Documento para o encontro de especialistas em aspectos da discriminação racial relativos ao gênero. Revista de Estudos Feministas, 10(1), 171-188.

Della Porta, D., Diani, M. (2006). Social movements: An introduction. 2. ed. Oxford: Wiley-Blackwell.

Diniz, A. P. R., Marcondes, M. M. (2016). MuIheres em cena: repertórios e estratégias de ação na $5^{\text {a }}$ Conferência de Políticas para as 


\section{ENTRE NEGOCIAÇÃo E CONFLITO: UMA ANÁLISE DA 5a CONFERÊNCIA DE POLítICAS PARA AS MULHERES DE SÃO PAULO}

Mulheres da cidade de São Paulo. In: XL Encontro da Associação Nacional de Pós-Graduação e Pesquisa em Administração (pp. 1-16). Costa do Sauípe. Anais... Costa do Sauípe: ANPAD.

Faria, C. F., Silva, V. P., Lins, I. L. (2012). Conferências de políticas públicas: Um sistema integrado de participação e deliberação? Revista Brasileira de Ciência Política, (7), 249-284.

Filgueira, F. (2013). Los regímenes de bienestar en el ocaso de la modernización conservadora: Posibilidades y límites de la ciudadanía social em América Latina. Revista Uruguaia Ciência Política, 22(n. especial), 10-27.

Fligstein, N., Mcadam, D. (2011). Toward a general theory of strategic action fields. Sociological Theory, (29), 1-26.

Gerring, J. (2010). Case selection for case-study analysis: Qualitative and quantitative techniques. In: J. Box-Steffensmeier, $\mathrm{H}$. Brady, D. Collier. The Oxford Handbook of Political Methodology. Oxford, UK: Oxford University Press.

Gibbs, G. (2009). Análise de dados qualitativos. Porto Alegre: Bookman.

Gohn, M. da G. M. (2008). O protagonismo da sociedade civil: movimentos sociais, ONGs e redes solidárias. 2. ed. São Paulo: Cortez.

Keck, M. E. (2010). A estruturação do PT: Legislação eleitoral e organização partidária. In: Keck, Margaret E. PT - A lógica da diferença: o partido dos trabalhadores na construção da democracia brasileira. Rio de Janeiro: Centro Edelstein de Pesquisas Sociais, pp. 127-175.

Marcondes, M. M., Diniz, A. P. R., \& Farah, M. F. S. (2016). Transversalidade de gênero: Uma análise sobre as transformações do conceito na institucionalização de políticas para as mulheres no Brasil. In: Encontro anual da ANPOCS, 40o, 2016, Caxambu. (pp. 1-30). Anais... Caxambu: ANPOCS.

Martes, A. C. B., \& Araujo, T. L. de. (2016). Participação social no Brasil: os pressupostos inatingíveis e as boas práticas possíveis. In: C. A. P. de Faria, C. V. Rocha, C. A. C. Filgueiras, L. G. Souki. (Orgs.). Políticas públicas na América Latina: novas territorialidades e processos. Porto Alegre: Editora da UFRGS/CEGOV, pp. 262-292.

Prefeitura de São Paulo. (2017). $1^{\circ}$ Plano Municipal de Políticas para as mulheres. São Paulo: SMPM-SP.

Prefeitura de São Paulo (2015a). Portaria $n$. 11, de 30 de julho de 2015. Institui o Regimento Interno da $5^{\text {a }}$ Conferência Municipal de Políticas para as Mulheres. Portaria, São Paulo, set.

Prefeitura de São Paulo (2015a). Regulamento Interno da $5^{a}$ Conferência Municipal de Políticas para as Mulheres da cidade de São Paulo. Define as normas de funcionamento da $5^{\text {a }}$ Conferência Municipal de Políticas para as Mulheres. Regulações, São Paulo, set.

Ramos, A. (2013). Conferência Nacional de Políticas para as Mulheres: interações discursivas e implicações para a legitimidade 
epistêmica. In: L. Avritzer, \& C. H. L. Souza (Orgs.). Conferências Nacionais: atores, dinâmicas participativas e efetividade, (pp. 95-124). Brasília: IPEA,

Ribeiro, U. C., Alencar, J. L. O., Lima, P. P. F., Souza, C. H. L. de; Cruxên, I. A. (2015). Experiências de monitoramento dos resultados de conferências nacionais - elementos para a discussão sobre efetividade da participação na gestão pública. Revista do Serviço Público, 66(1), 55-74.

Rocha, E. (2008). A Constituição Cidadã e a institucionalização dos espaços de participação social: Avanços e desafios. In: F. T. Vaz. (Org.). 20 anos da Constituição Cidadã: Avaliação e desafios da seguridade social (pp. 131-148). Brasília: IPEA.

Silva, C. S. M. (2016). Feminismo popular e luta antissistêmicas. Recife: SOS Corpo.

Souza, C. H. L. de, Cruxên, I. A., Lima, P. P. F., Alencar, J. L. O., Ribeiro, U. C. (2013). Conferências típicas e atípicas: Um esforço de caracterização do fenômeno político. In: Avritzer, Leonardo; Souza, Clóvis H. L. de
(Orgs.). Conferências Nacionais: atores, dinâmicas participativas e efetividade (pp. 2552). Brasília: IPEA.

Souza, C. H. L. de, \& Pires, R. R. C. (2012). Conferências Nacionais como interfaces socioestatais: Seus usos e papéis na perspectiva de gestores federais. Revista do Serviço Público, 63(4), 499-518.

Souza-Lobo, E. (1991). A classe operária tem dois sexos. 2. ed. São Paulo: Perseu Abramo.

Stake, R. (1998). Case Studies In: Denzin, Norman; \& Lincoln, Yvona (Orgs.). Strategies of Qualitative Inquiry. California: Sage Publications.

Tilly, C. (2008). Contentious Performances. Cambridge: Cambridge Press.

Veras, R. (2005). O sindicalismo metalúrgico, o "festival de greves" e as possibilidades de contrato coletivo nacional. In: Santos, Boaventura de Souza (Org.). Trabalhar o mundo: Os caminhos do novo internacionalismo operário (pp. 210-235). São Paulo: Civilização Brasileira. 